\title{
Further investigation of the relationship between cultural intelligence and expatriate career intentions
}

\author{
Ana Camargo ${ }^{1,2}\left(\mathbb{D} \cdot\right.$ Martin Storme $^{3,4} \cdot$ Pinar Çelik $^{5}$
}

Received: 6 August 2018 / Accepted: 24 April 2019 / Published online: 8 May 2019

(C) Springer Nature B.V. 2019

\begin{abstract}
Previous research has shown that cultural intelligence is a positive predictor of expatriate career intentions among university students, but little is known about the "how" of this relationship. In a first study $(N=241)$ we provide evidence for the incremental validity of cultural intelligence, by showing that cultural intelligence predicts expatriate career intentions over and above emotional intelligence and the five-factor model of personality. In a second study $(N=469)$, we find that expatriate career self-efficacy mediates the link between cultural intelligence and expatriate career intentions. Theoretical and practical implications are discussed.
\end{abstract}

Keywords Cultural intelligence $\cdot$ Expatriate career intentions $\cdot$ Self-efficacy

\section{Résumé}

Analyse approfondie de la relation entre l'intelligence culturelle et les intentions d'expatriation professionnelle Des recherches antérieures ont montré que l'intelligence culturelle est un prédicteur positif des intentions d'expatriation parmi les étudiants universitaires, mais l'on sait peu de choses sur le "pourquoi" de cette relation. Dans une première étude $(N=241)$, nous démontrons la validité incrémentale de l'intelligence culturelle en montrant que l'intelligence culturelle prédit les intentions d'expatriation au-delà de l'intelligence émotionnelle et du modèle de personnalité à cinq facteurs. Dans une deuxième étude $(N=469)$, nous montrons que l'auto-efficacité relative à l'expatriation joue un rôle médiateur dans la relation entre

Ana Camargo

anamis@live.com

1 LaPEA, Université Paris Descartes, Paris, France

2 Le Lab RH, Paris, France

3 IESEG School of Management, Lille, France

4 LEM-CNRS 9221, Lille, France

5 Centre Emile Bernheim, Solvay Brussels School of Economics and Management, Université Libre de Bruxelles, Brussels, Belgium 
l'intelligence culturelle et les intentions d'expatriation. Les implications théoriques et pratiques sont discutées.

\section{Zusammenfassung}

Untersuchung des Zusammenhangs zwischen kultureller Intelligenz und beruflichen Absichten von Expatriates Frühere Untersuchungen haben gezeigt, dass kulturelle Intelligenz ein positiver Prädiktor der Karriereabsichten von Expatriates unter Universitätsstudenten ist, aber es ist wenig über das "Wie" dieser Beziehung bekannt. In einer ersten Studie $(N=241)$ liefern wir Evidenz für die inkrementelle Validität der kulturellen Intelligenz, indem wir zeigen, dass sie die Karriereabsichten von Expatriates über emotionale Intelligenz und das Fünf-Faktoren-Modell der Persönlichkeit hinaus voraussagt. In einer zweiten Studie $(N=469)$ finden wir, dass die Selbstwirksamkeit der Expatriates als Mediator zwischen kultureller Intelligenz und den beruflichen Absichten vermittelt. Theoretische und praktische Implikationen werden diskutiert.

\section{Resumen}

Investigación adicional de la relación entre la inteligencia cultural y la intención de expatriación profesional Investigaciones anteriores han mostrado que la inteligencia cultural es un predictor positivo de la intención de expatriación profesional en estudiantes universitarios, pero se sabe poco sobre el "cómo" de la relación. En un primer estudio $(N=241)$, demostramos la validez de predicción incremental de la inteligencia cultural, mostrando que la inteligencia cultural predice la intención de expatriación profesional más allá de la inteligencia emocional y del modelo de la personalidad en cinco factores. En un segundo estudio $(N=469)$, encontramos que la autoeficacia relativa a la expatriación profesional es un mediador de la relación entre la inteligencia cultural y la intención de expatriación profesional. Las implicaciones teóricas y practicas de los resultados son analizadas.

\section{Introduction}

Expatriation has benefits for companies, but also for workers who can acquire crosscultural knowledge and develop social skills that are important for a career (Fang, Jiang, Makino, \& Beamish, 2010; Vaiman, Haslberger, \& Vance, 2015). The awareness of the benefits of expatriation among workers has even contributed to the growing phenomenon of self-initiated expatriation (Doherty et al., 2013; Vaiman et al., 2015). It is important for practitioners like career managers, counsellors, and teachers, to understand the antecedents of expatriate career intentions among students, in order to find methods to foster intentions to expatriate.

Several researchers have therefore focused on investigating the factors associated with intentions to expatriate and some have identified cultural intelligence as an important predictor (Krishnan \& Kirubamoorthy, 2017; Presbitero \& Quita, 2017). The relationship between cultural intelligence and expatriate career intentions needs however further investigation. For example, little is known about the real 
incremental predictive power of cultural intelligence over and beyond other possible predictors of expatriate career intentions-such as personality traits and emotional intelligence-which are also known to be correlated with cultural intelligence (Ang et al., 2007; Harari, Reaves, Beane, Laginess, \& Viswesvaran, 2018). Does cultural intelligence really add something to the prediction of expatriate career intentions or is it redundant with more traditional constructs? More research is also needed on the psychological mechanisms that explain the relationship between cultural intelligence in regard to expatriate career intentions. How can we explain that cultural intelligence contributes to expatriate career intentions?

Our aims with the current research are (1) to provide evidence for the incremental validity of cultural intelligence beyond personality and emotional intelligence when predicting expatriate career intentions, and (2) to test a model of the relationship between cultural intelligence and expatriate career intentions based on self-efficacy theories which conceptualizes expatriate career self-efficacy as an important mediator (Ireland \& Lent, 2018; Lent \& Brown, 2013; Lent, Brown, \& Hackett, 1994; Weerasinghe \& Kumar, 2015).

\section{Cultural intelligence and expatriate career intentions}

Due to globalization, working in a foreign country is becoming more and more frequent among educated workers (Caligiuri \& Bonache, 2016; Liu \& Giroud, 2016). Such expatriations can be imposed by the constraints of the job market, but they can also be desired by workers themselves (Caligiuri \& Bonache, 2016; Liu \& Giroud, 2016; Vaiman et al., 2015). The phenomenon of self-initiated expatriation-moving to another country without being sent by an employer-is gaining in popularity (Doherty et al., 2013; Vaiman et al., 2015). This is because working abroad is increasingly considered as an asset in career paths, as it allows individuals to gain cross-cultural insights, to acquire knowledge that is not available in the country of origin, and to train adaptation skills (Fang et al., 2010; Vaiman et al., 2015). The benefits of hiring candidates with professional experience in another country are emphasized more and more (Pérez \& Pla-Barber, 2005). Companies are looking to hire global leaders that will give them the competitive edge that will make the difference (Li \& Lowe, 2016). As a result, the desire and curiosity regarding working abroad through a self-initiated expatriation can start early on during individuals' higher education.

Previous research has tried to establish the factors that explain expatriate career intentions among university students. It has been shown that cultural intelligence is a positive predictor of expatriate career intentions (Presbitero \& Quita, 2017). Cultural intelligence can be defined as an individual's ability to function effectively in culturally diverse situations that result from differences in race, ethnicity and nationality (Ang et al., 2007). Cultural intelligence has been conceptualized as a multidimensional construct (Ang et al., 2007). The metacognitive dimension of cultural intelligence refers to the awareness of one's own thought processes while interacting with people from other cultural backgrounds (Ang \& Van Dyne, 2015; Van Dyne, Ang, \& Koh, 2008). When interacting with people from other cultures, individuals 
with high levels of metacognitive cultural intelligence tend to consciously monitor their cultural assumptions and update them when necessary (Van Dyne et al., 2008). The cognitive dimension of cultural intelligence (Ang \& Van Dyne, 2015; Van Dyne et al., 2008) refers to the knowledge of economic, legal and social systems as well as the values unique to each culture (Van Dyne et al., 2008). Individuals gain such cultural knowledge through their education and personal experience (Ang et al., 2007). The motivational dimension of cultural intelligence refers to the intrinsic drive to learn about different cultures, to interact with people from different cultural backgrounds, and to be in culturally diverse situations (Ang et al., 2007). This dimension also includes self-efficacy beliefs pertaining to the ability to deal with cultural diversity (Van Dyne et al., 2008). Finally, the behavioral dimension of cultural intelligence refers to the ability to adopt appropriate verbal and nonverbal behavior during social interactions with people from different cultural backgrounds (Ang, Van Dyne, $\&$ Koh, 2006). Individuals with high levels of behavioral cultural intelligence use culturally appropriate words, voice tones, facial expressions, or gestures (Ang et al., 2007).

To explain the relationship between cultural intelligence and expatriate intentions, it is reasoned that culturally intelligent individuals, because of their heightened knowledge and skills, are more interested in an expatriate career as they feel confident that they could adjust to a new culture and handle working overseas. The desire to have a career in another country has indeed been shown to be strongly influenced by self-efficacy beliefs (Weerasinghe \& Kumar, 2015). More specifically, the confidence one has in his/her ability to expatriate - that is to adjust to and work in a new culture-plays a major role in explaining expatriate career intentions (Weerasinghe \& Kumar, 2015). Consequently, the factors contributing to explaining expatriate career intentions are probably partly those that are predictive of crosscultural adjustment during expatriation, as the awareness of these resources might increase self-efficacy beliefs among individuals who are interested in working abroad. The literature on the predictors of cross-cultural adjustment shows that cultural intelligence contributes to cross-cultural adjustment, but also other predictors, such as emotional intelligence (Ang et al., 2007; Lee, Veasna, \& Sukoco, 2014) and personality traits (Caligiuri, 2001; Harari et al., 2018) that are also known correlates of cultural intelligence.

\section{Incremental validity of cultural intelligence}

Previous research has established that cultural intelligence is positively related to expatriate career intentions but did not provide evidence for the incremental predictive power of cultural intelligence over and beyond other constructs that might provide alternate explanations as to why cultural intelligence is related to expatriate career intentions. Expatriate career intentions have been shown to be strongly related to self-efficacy beliefs pertaining to the ability to adjust to a new culture and work efficiently in a new culture (Weerasinghe \& Kumar, 2015). Consequently, as individuals are likely aware of the resources that would help them in a new culture, 
the resources that contribute to cross-cultural adjustment could also directly contribute to intentions to expatriate.

The social cognitive model of Career Self-Management (Lent \& Brown, 2013), provides an interesting framework to conceptualize the mechanism underlying the relationship between cultural intelligence and expatriate career intentions. The Career Self-Management model is based on Social Cognitive Career Theory, and complements the latter with factors that explain general career decision-making processes. Indeed, SCCT describes key stages involved in careers: development of basic academic and career interests, educational and career choice, acquisition of academic and career success, and career satisfaction/well-being. It enables predictions of the specific educational and occupational fields individuals will find satisfaction and success in. Complementing the former, the Career Self-Management model sheds light on the processes behind individuals' adaptive career behaviors, or the how that explains how individuals manage their career and education, across occupational fields. These adaptive career behaviors include "self-assertion, general planning, career advancement and cognitive coping skills" (Lent \& Brown, 2013, p. 559).

The Career Self-Management model is inspired by Bandura's General Social Cognitive Theory (1977), and places self-efficacy beliefs at the center of adaptive career behaviors (Lent \& Brown, 2013; Lent et al., 1994). More specifically, individuals wishing to accomplish a specific career outcome or behavior, are more likely to do so through high self-efficacy expectations and outcome expectations that will influence their career goals, actions and outcomes. Self-efficacy expectations are influenced by sources of efficacy information as well as personality and contextual factors. Altogether, self-efficacy, goals, actions, person inputs (including personality, abilities and predispositions) and contextual factors, all increase the likelihood of adaptive career behaviors.

In the same way that SCCT had been successfully applied to general career decision making processes, previous research has shown that the Career Self-Management model has been applied to job searching (Lim, Lent, \& Penn, 2016), multiple role planning (Roche, Daskalova, \& Brown, 2017), career exploration and career decision making activities (Ireland \& Lent, 2018). Applying the reasoning of the Career Self-Management model to expatriate decisions, one could reason that expatriate career intentions are strongly influenced by self-efficacy beliefs pertaining to expatriation, which are reinforced by available person inputs or abilities, including but not limited to, cultural intelligence (see Figure 1).

The literature on cross-cultural adjustment showed that emotional intelligence is an important resource contributing to cross-cultural adjustment among expatriates (Konanahalli \& Oyedele, 2016; Koveshnikov, Wechtler, \& Dejoux, 2014). Emotional intelligence can be defined as the ability to perceive, assimilate, understand, and manage emotions to facilitate social interactions (Wong \& Law, 2002). Emotional intelligence is fundamentally about social interactions, sharing some resemblance with cultural intelligence (Ang \& Van Dyne, 2015; Brislin, Worthley, \& Macnab, 2006; Earley \& Mosakowski, 2004; Van Dyne et al., 2008). Emotional intelligence and cultural intelligence both rely on the ability to perceive and interpret cues when communicating with others, demonstrating sensitivity to complex 


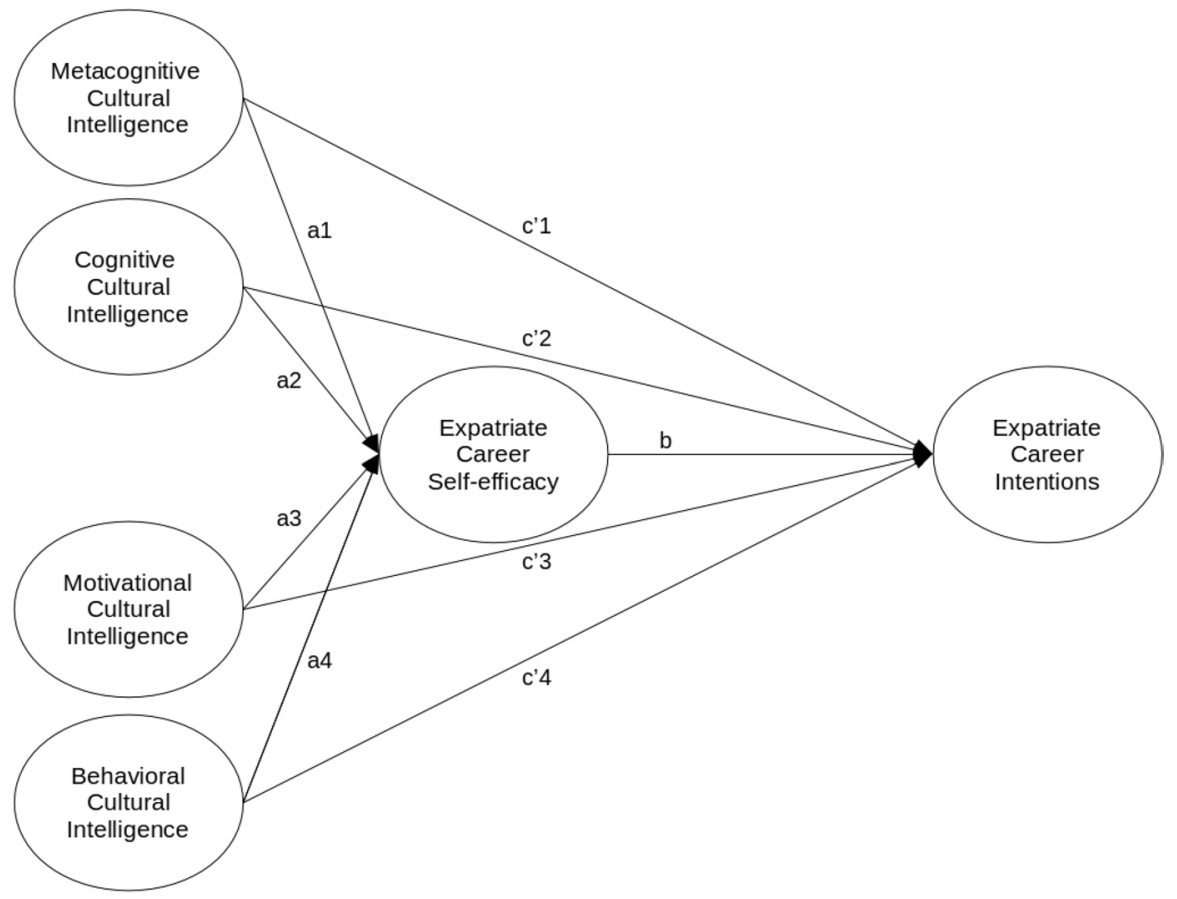

Figure 1 A simplified version of the proposed mediation model (Study 2) with expatriate career selfefficacy as mediator of the effect of cultural intelligence dimensions on expatriate career intentions (see Table 4 for estimates)

situations and behavioral flexibility, which translate into effective interactions with others (Crowne, 2009).

It has been shown that emotional intelligence plays a mediating role between cultural intelligence and cross-cultural adjustment (Lin, Chen, \& Song, 2012), seen as a career outcome in the Career Self-Management (CSM) model. In addition, it has been found that emotional intelligence predicts career adaptability, another important outcome in the CSM model (Coetzee \& Harry, 2014). It could therefore be hypothesized that the relationship between cultural intelligence, a personal ability in the CSM model, and expatriate career intentions (or expatriate career goals in the CSM model), is fully explained by correlations of the two constructs with another personal ability: emotional intelligence, as an antecedent of expatriate career intentions. Nevertheless, we have reasons to believe that this is not the case and that cultural intelligence, is a personal ability that has incremental predictive power beyond emotional intelligence when predicting the career related goal of expatriate career intentions.

Skills that are more specifically associated with emotional intelligence are the ability to perceive and interpret emotional cues, the understanding of emotions, the facilitation of emotional thoughts, empathy, emotional expression, and effective emotion management (Crowne, 2009). Skills that are more specifically associated with cultural intelligence are the ability to perceive and interpret 
cultural cues, the processing of cultural knowledge and information, the suspension of judgment, the exhibition of appropriate cultural behaviors, and the motivation to learn about cultures (Crowne, 2009). Cultural intelligence, seen as a personal ability within the CSM model, should thus be more appropriate than emotional intelligence when it comes to predicting career-related goals that are related to culturally diverse environments (Ang \& Van Dyne, 2015; Van Dyne et al., 2008). Supporting this reasoning, cultural intelligence has been shown to have incremental validity over and above emotional intelligence when predicting cultural decision making (Van Dyne et al., 2008). We therefore hypothesize that cultural intelligence has incremental validity beyond emotional intelligence when predicting expatriate career intentions.

Personality-notably extroversion, emotional stability, and openness-is another known predictor of cross-cultural adjustment (Harari et al., 2018) that could explain the observed correlations between cultural intelligence and expatriate career intentions. Research on the relations between personality and cultural intelligence has shown that openness and extroversion are also correlated with several dimensions of cultural intelligence. One could therefore wonder whether the relationship between cultural intelligence and expatriate career intentions cannot be explained by correlations of the two constructs with basic personality traits. Cultural intelligence probably taps into personality traitswith openness to new cultural experiences-, but it also taps into other constructs that cannot be reduced to personality traits, such as the self-efficacy beliefs pertaining to the ability to adjust to new cultures. Consequently, we hypothesize that cultural intelligence has incremental validity beyond the five factor model when predicting expatriate career intentions.

\section{The mediating role of self-efficacy}

What does explain the relationship between cultural intelligence and expatriate career intentions if not emotional intelligence and personality? As mentioned previously, one could reason that expatriate career intentions are strongly influenced by self-efficacy beliefs pertaining to expatriation, reinforced by person inputs or abilities, such as cultural intelligence (see Figure 1).

There is already partial support for this model in the literature. For example, Weerasinghe and Kumar (2015) found that expatriate career self-efficacy is an important predictor of expatriate career intentions. This theoretical model could also explain some interesting findings regarding the relationship between the dimensions of cultural intelligence and expatriate career intentions. Previous research indeed showed that it is mostly the motivational dimension of cultural intelligence that is predictive of expatriate career intentions, above and beyond the cognitive, metacognitive and behavioral dimensions of cultural intelligence (Schlägel \& Sarstedt, 2016). As the motivational dimension also includes a measure of self-efficacy beliefs regarding one's ability to cope with cultural challenges, our model based on the Career Self-Management model that emphasizes the role of self-efficacy beliefs 
would explain why motivational cultural intelligence is the main predictor of expatriate career intentions across the four dimensions of cultural intelligence. Altogether, we hypothesize that expatriate career self-efficacy should have a mediating role between cultural intelligence - and in particular, its motivational dimensionand expatriate career intentions.

\section{Aims of the study}

We seek to further explore the relationship between cultural intelligence and expatriate career intentions with two empirical studies. In the first study, we are interested in the incremental predictive validity of cultural intelligence over and beyond emotional intelligence and personality traits from the five factor model. We hypothesize that cultural intelligence-and especially its motivational dimension-positively predicts expatriate career intentions above and beyond emotional intelligence and the five personality factors.

In the second study, we test the mediation model described above. We hypothesize that cultural intelligence predicts expatriate career intentions through expatriate career self-efficacy (see Figure 1). In other words, being able to deal with cultural problems, should be associated with higher levels of expatriate career self-efficacy, which should in turn be associated with higher expatriate career intentions. Altogether, we hypothesize that expatriate career self-efficacy mediates the relationship between cultural intelligence-especially its motivational dimension-and expatriate career intentions.

\section{Study 1}

The aim of the first study was to investigate the incremental validity of cultural intelligence over and beyond personality and emotional intelligence when predicting expatriate career intentions among university students.

\section{Method}

\section{Participants}

The sample consisted of 241 first year French (from Paris area) business administration university students $\left(M_{\text {age }}=18.41, S D_{\text {age }}=0.85\right.$, ranging from 18 to 23$)$. In the sample, $50.62 \%$ of the participants were male $(n=122)$, and $49.38 \%$ were female $(n=119)$. We do not have information about the ethnicity of participants as ethnicity statistics are illegal in France. 


\section{Measures}

Cultural intelligence (CQS, Van Dyne et al., 2008). We used the Cultural Intelligence Scale to measure cultural intelligence. The questionnaire measures four dimensions of cultural intelligence. Metacognitive $C Q$ refers to the awareness of cultural thought processes while interacting with people with another cultural background (4 items: e.g. "I am conscious of the cultural knowledge I use when interacting with people with different cultural backgrounds"), cognitive $C Q$ refers to the knowledge of norms, practices, and conventions of different cultures (6 items: e.g. "I know the legal and economic systems of other cultures"), motivational $C Q$ refers to the desire to learn about and be in situations characterized by cultural diversity ( 5 items: e.g. "I enjoy interacting with people from different cultures") and behavioral $C Q$ refers to the ability to adopt verbal and nonverbal behaviors that are functional when interacting with people with different cultural backgrounds (5 items: e.g. "I change my verbal behavior (e.g., accent, tone) when a cross-cultural interaction requires it"). We used a 7-point Likert scale ranging from 1 (Totally disagree) to 7 (Totally agree). Two French native speakers translated the original items into French, and an independent English native speaker translated them back into English for validation purposes. The CQS has been shown to have good psychometric properties with satisfactory levels of scale-score reliability, and construct validity (Ang et al., 2007). The CQS is correlated with emotional intelligence and the Big 5 personality traits, but also with various indicators of cross-cultural competence (Ang et al., 2007). The original validation study also provides support for the discriminant validity of CQ (Ang et al., 2007). In our sample, the CQS exhibited satisfactory scale-score reliability, with Cronbach's $\alpha$ s of $.82, .79, .78$, and .84 for respectively metacognitive CQ, cognitive $\mathrm{CQ}$, motivational $\mathrm{CQ}$, and behavioral $\mathrm{CQ}$.

Big Five personality traits (Gosling, Rentfrow, \& Swann Jr, 2003). The Big Five personality traits were assessed with the French version of the Ten-Item Personality Inventory. The TIPI is a 10-item self-report questionnaire that measures extroversion, agreeableness, conscientiousness, emotional stability, and openness to experience. The TIPI has been built as a short scale with large content coverage to maximize content validity. Consequently, the measurement model of the TIPI is more formative than reflective in nature, as it is evidenced by empirical research (Myszkowski, Storme, \& Tavani, 2018). The Cronbach's $\alpha$ is therefore not a relevant indicator to assess the quality of the scale (Gosling et al., 2003; Storme, Tavani, \& Myszkowski, 2016). The reliability of the TIPI is better assessed by test-retest reliability indicators, which have been shown to be satisfactory in both English and French speaking samples (Gosling et al., 2003; Storme et al., 2016).

Emotional intelligence (Wong \& Law, 2002). We used the Emotional Intelligence scale designed by Wong and Law (2002). The scale assesses the following four dimensions of emotional intelligence: Self-emotion appraisal (4 items: e.g. "I really understand what I feel"), Others' emotion appraisal (4 items: e.g. "I am a good observer of others' emotions"), Use of emotion (4 items: e.g. "I am a self- 
motivated person") and Regulation of emotion (4 items: e.g. "I have good control of my own emotions"). The response scale was a 7-point Likert scale ranging from 1 (Totally disagree) to 7 (Totally agree). Previous research has shown that the original scale has satisfactory psychometric properties and construct validity (Wong \& Law, 2002). Two French native speakers translated the original items into French, and an independent English native speaker then translated them back into English for validation purposes. The scale showed satisfactory scale-score reliability in our sample with Cronbach's $\alpha$ s of $.87, .86, .85$, and .89 for respectively self-emotion appraisal, others' emotion appraisal, use of emotion, and regulation of emotion. The overall Cronbach's $\alpha$ was also satisfactory: .85 .

Expatriate career intentions (Weerasinghe \& Kumar, 2015). We used a 5-item scale to measure students' expatriate career intentions (Weerasinghe \& Kumar, 2015). Responses were given on a 7-point Likert scale ranging from 1 (strongly disagree) to 7 (strongly agree). Sample items of expatriate career intentions are "I intend to work in a foreign country in the near future (i.e. soon after graduation)" and "It is likely that I will try to work in a foreign country in the near future". Two French native speakers translated the original items into French, and an independent English native speaker then translated them back into English for validation purposes. Previous empirical research has shown that the scale has satisfactory psychometric properties with a Cronbach's $\alpha$ of .93. Regarding construct validity, expatriate career intentions are positively related with attitudes towards expatriation, expatriate career self-efficacy, and actual behaviors of expatriation (Weerasinghe \& Kumar, 2015). The scale also had satisfactory psychometric properties in our sample (Cronbach's $\alpha$ was .94).

\section{Procedure}

Students participated in this study as an extra credit opportunity. Questionnaires were filled in online. Anonymity and confidentiality were guaranteed. It was required that participants answer all items before submitting their responses in the setting of the online survey, consequently, we had no missing data among participants who took all the questionnaires.

\section{Results}

\section{Preliminary analyses}

Descriptive statistics are reported in Table 1. Consistent with our hypotheses, we found that general emotional intelligence was positively related to all four dimensions of cultural intelligence. Openness was positively related to metacognitive $\mathrm{CQ}$, cognitive $\mathrm{CQ}$, and motivational $\mathrm{CQ}$, but not to behavioral CQ. Furthermore, we found that three of the four dimensions of cultural intelligence (metacognitive, cognitive and motivational) and openness to experience were positively related to 


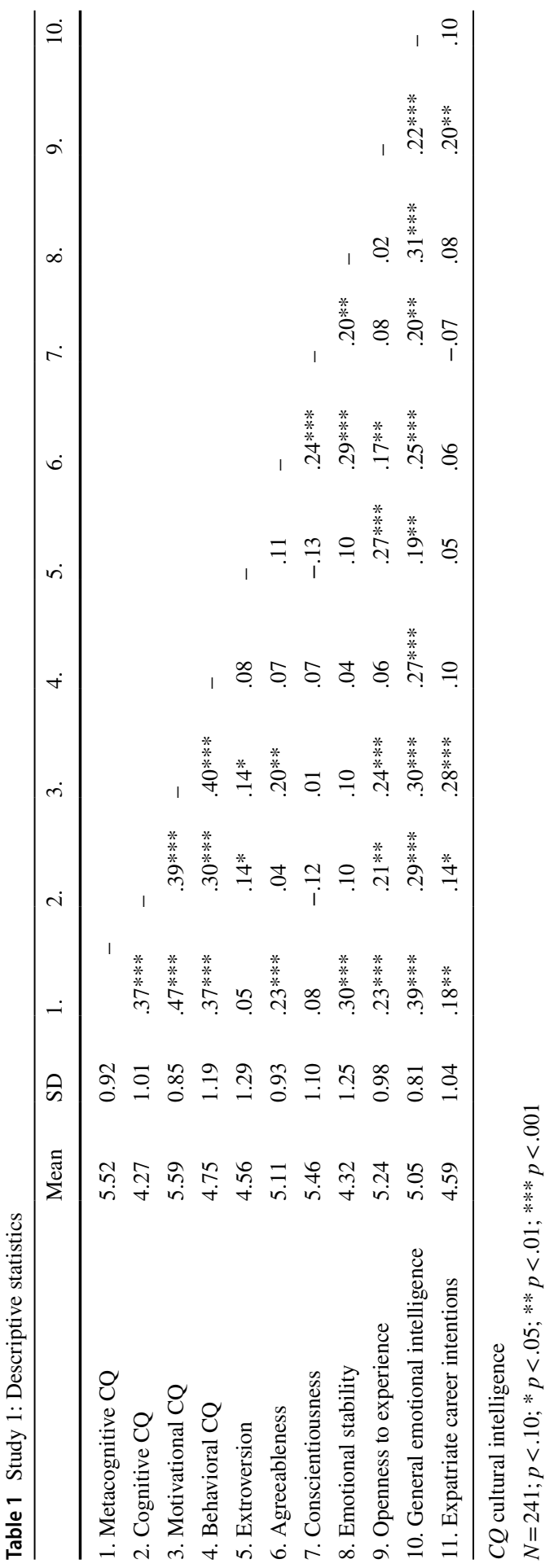


expatriate career intentions. Contrary to our expectations, emotional intelligence was not related to expatriate career intentions.

In order to assess the factor structure of the scales, we ran a confirmatory factor analysis for ordinal variables using the R package lavaan (Rosseel, 2012). Ordered indicators such as responses to Likert scales should be handled with estimation methods that take into account the ordinal nature of the data (Wirth \& Edwards, 2007). The most often employed approach to modeling ordinal data relies on the weighted least squares means and variance adjusted estimator (WLSMV) and consists in modeling thresholds for each indicator that describe at which level of the latent trait the specific category is most likely chosen (Rosseel, 2012).

The model was built according to the theoretical structure of the emotional intelligence, the cultural intelligence, and the expatriate career intentions scales. The items of the cultural intelligence scale loaded on their respective latent variable (metacognitive, cognitive, motivation, or behavior). The four latent variables were allowed to correlate. The items of the emotional intelligence scale loaded on their respective latent variable (self-emotion appraisal, others' emotion appraisal, use of emotion, or regulation of emotion), and the four subdimensions loaded in turn on a second-order factor of general emotional intelligence. The items of expatriate career intentions loaded on one latent variable. The Big Five were not included in this analysis as using latent variable modeling is not relevant on such a brief scale (Gosling et al., 2003; Storme et al., 2016). The correlations between all constructs were freely estimated in the analysis.

Regarding model fit, we used four statistical indices: The $\chi^{2} / \mathrm{df}$ ratio (should be less than 3), the Comparative Fit Index (CFI should be greater than .90), the Standardized Root Mean Square Residual (SRMR should be less than .08), and the Root Mean Square Error of Approximation (RMSEA should be less than .08). The model showed acceptable fit $\chi^{2}(760)=1557.72, \chi^{2} / \mathrm{df}=2.05$, $\mathrm{CFI}=.924, \mathrm{SRMR}=.080, \mathrm{RMSEA}=.066$. All factor loadings were significant and medium to large in magnitude (all loadings were greater than .50). With this first analysis, we concluded that the data supported our theoretical expectations regarding the structural validity of the investigated constructs.

\section{Incremental validity analyses}

To test whether cultural intelligence has incremental predictive validity over and beyond the Big Five personality traits and emotional intelligence when predicting expatriate career intentions, we conducted a stepwise regression and tested whether the proportion of variance in expatriate intentions is significantly larger when cultural intelligence is used as a predictor. In the first step, expatriate career intentions was regressed on the Big Five (extroversion, agreeableness, conscientiousness, emotional stability, and openness to experience) and emotional intelligence. In the second step, expatriate career intentions was regressed both on the Big Five traits and emotional intelligence and all four cultural intelligence dimensions. The results are reported in Table 2. 
Table 2 Study 1: Stepwise regression results

\begin{tabular}{lcc}
\hline Variable & Step 1 & Step 2 \\
\hline General emotional intelligence & .01 & -.01 \\
Extroversion & -.05 & -.05 \\
Agreeableness & .02 & -.01 \\
Conscientiousness & -.13 & -.11 \\
Emotional stability & .08 & .07 \\
Openness to experience & $.21^{* *}$ & $.17^{*}$ \\
Metacognitive CQ & & .03 \\
Cognitive CQ & & -.01 \\
Motivational CQ & & $.24^{* *}$ \\
Behavioral CQ & .06 & .00 \\
$R^{2}$ & $F_{(6,234)}=2.61, p=.018$ & .12 \\
$F$ & & $F_{(4,230)}=3.47, p=.009$ \\
\hline
\end{tabular}

$C Q$ cultural Intelligence

$N=241 ; * p<.05 ; * * p<.01 ; * * * p<.001$

In line with our hypothesis, we found that cultural intelligence has increased predictive value for expatriate career intentions $F(4,230)=3.47, p=.009$, beyond personality and emotional intelligence. Our analyses revealed that only motivational CQ $(B=.24, p<.01)$ and openness to experience $(B=.17, p<.05)$ predicted expatriate career intentions when controlling for all predictors in the same analysis.

\section{Discussion}

Our aim with Study 1 was to test the incremental validity of cultural intelligence in predicting expatriate career intentions, compared to other factors commonly seen in the expatriate career-related literature, including emotional intelligence and personality. Our findings are in line with our expectations as cultural intelligence-and especially its motivational dimension-had incremental predictive power over emotional intelligence and the five factor model of personality. This means that the relationship between cultural intelligence and expatriate career intentions cannot be fully explained by the fact that both constructs are correlated with emotional intelligence or the same personality traits.

Our findings suggest that it is mostly the motivational dimension of cultural intelligence that contributes to the incremental validity of cultural intelligence over and beyond other predictors. Motivational CQ, or the desire to learn about and be in situations characterized by cultural diversity, is based on an intrinsic interest as well as the confidence in one's cross-cultural effectiveness (Ang et al., 2007). Compared to the metacognitive, cognitive and behavioral dimensions of cultural intelligence, the motivational dimension of cultural intelligence is the only dimension that incorporates intrinsic interest as well as a measure 
of self-efficacy beliefs, which come into play when predicting expatriate career intentions. Intentions, are themselves characterized by a determination to act a certain way, which is reflected in expatriate career intentions, as the likeliness and the future efforts that will be provided towards a future expatriation. Individuals with high levels of motivational cultural intelligence are probably more likely to have an incentive that drives them to provide the necessary efforts required by a future expatriation.

\section{Study 2}

The aim with Study 2 was to extend the findings of Study 1 and to test a model inspired from the Career Self-Management model (Lent \& Brown, 2013), in which expatriate career self-efficacy mediates the relationship between the personal ability of cultural intelligence and the career goal of expatriate career intentions.

\section{Method}

\section{Participants}

The sample consisted of 469 third year French (from Paris area) business administration university students $\left(M_{\text {age }}=20.62, S D_{\text {age }}=0.90\right.$, ranging from 19 to 27 years). In the sample, $41.79 \%$ of the participants were male $(n=196)$, and $58.21 \%$ were female $(n=273)$. We do not have information about the ethnicity of participants as ethnicity statistics are illegal in France.

\section{Measures}

Cultural intelligence (CQS, Van Dyne et al., 2008). We used the same Cultural Intelligence Scale as in Study 1 to measure cultural intelligence. In this sample, Cronbach's as were .81, .77, .82, and .81 respectively for metacognitive CQ, cognitive CQ, motivational $\mathrm{CQ}$, and behavioral $\mathrm{CQ}$.

Expatriate career self-efficacy and intentions (Weerasinghe \& Kumar, 2015). We used a 6-item scale to measure students' expatriate career self-efficacy (Weerasinghe \& Kumar, 2015), and the 5-item scale to measure students' expatriate career intentions as in Study 1 (Weerasinghe \& Kumar, 2015). Responses were given on a 7-point Likert scale ranging from 1 (strongly disagree) to 7 (strongly agree). Sample items of expatriate career self-efficacy are "I would feel comfortable pursuing a job in a foreign country on my own" and "If I wanted to, I could easily pursue a job in foreign country on my own". Two French native speakers translated the original items into French, and an independent English native speaker then translated them back into English for validation purposes. Previous empirical research has shown that both scales have satisfactory psychometric properties with Cronbach's 
Table 3 Study 2: Descriptive statistics

\begin{tabular}{lccccccc}
\hline & Mean & $S D$ & 1. & 2. & 3. & 4. & 5. \\
\hline 1. Metacognitive CQ & 5.37 & 0.92 & - & & & & \\
2. Cognitive CQ & 4.35 & 0.88 & .29 & - & & & \\
3. Motivational CQ & 5.56 & 0.92 & .43 & .27 & - & & \\
4. Behavioral CQ & 4.58 & 1.01 & .44 & .39 & .34 & - & .28 \\
5. Expatriate career self-efficacy & 5.22 & 1.10 & .32 & .22 & .47 &. \\
6. Expatriate career intentions & 4.26 & 1.23 & .29 & .17 & .42 & .18 & .72 \\
\hline
\end{tabular}

$C Q$ cultural intelligence

$N=469 ;$ all correlations are significant at $p<.001$

$\alpha$ of .84 for self-efficacy and .93 for intentions. Both scales also had satisfactory psychometric properties in our sample (Cronbach's $\alpha$ was .90 for self-efficacy, and .94 for intentions).

\section{Procedure}

Students participated in this study as an extra credit opportunity. Questionnaires were filled in online. Anonymity and confidentiality were guaranteed. We required that participants answer all items before they could submit their responses in the setting of the online survey, consequently, we had no missing data among participants who took all the questionnaires.

\section{Results}

\section{Preliminary analyses}

Descriptive statistics are reported in Table 3. Consistent with our hypotheses and with our expectations regarding convergent validity, correlations between cultural intelligence, expatriate career self-efficacy, and expatriate career intentions were all positive.

In order to assess the factor structure of the three scales, we ran a confirmatory factor analysis for ordinal variables using the $\mathrm{R}$ package lavaan (Rosseel, 2012). The model was built according to the theoretical structure of the three scales. The items of the cultural intelligence scale loaded on their respective latent variable (metacognitive, cognitive, motivation, or behavior). The four latent variables were allowed to correlate. The items of the expatriate career self-efficacy scale and the items of expatriate career intentions loaded on their respective latent variable. The correlations between all constructs were freely estimated in the analysis.

The model showed acceptable fit $\chi^{2}(419)=932.51, \chi^{2} / d f=2.23$, CFI $=.978$, $\mathrm{SRMR}=.047, \mathrm{RMSEA}=.051$. All factor loadings were significant and medium to large in magnitude (all loadings were greater than .50). With this first analysis, we 
Table 4 Unstandardized path coefficients of the structural mediation model (bootstrap estimates)

\begin{tabular}{llllcl}
\hline Effect & Path label & $B$ & $S E$ & $p$ value & $95 \%$ CI \\
\hline Direct effects & $\mathrm{a} 1$ & 0.11 & 0.11 & .29 & {$[-0.10 ; 0.34]$} \\
Of cultural intelligence & $\mathrm{a} 2$ & 0.09 & 0.09 & .95 & {$[-0.10 ; 0.26]$} \\
On expatriate career self-efficacy & $\mathrm{a} 3$ & 0.61 & 0.12 & $<.001$ & {$[0.40 ; 0.88]$} \\
& $\mathrm{a} 4$ & 0.11 & 0.10 & .25 & {$[-0.08 ; 0.30]$} \\
Direct effect of expatriate career & $\mathrm{b}$ & 1.03 & 0.07 & $<.001$ & {$[0.90 ; 1.17]$} \\
$\quad$ self-efficacy on intentions & & & & & \\
Direct effects & $\mathrm{c} 1^{\prime}$ & 0.14 & 0.12 & .23 & {$[-0.08 ; 0.38]$} \\
Of cultural intelligence & $\mathrm{c} 2^{\prime}$ & -0.03 & 0.10 & .78 & {$[-0.22 ; 0.16]$} \\
On expatriate career intentions & $\mathrm{c} 3{ }^{\prime}$ & 0.11 & 0.11 & .30 & {$[-0.10 ; 0.33]$} \\
& $\mathrm{c} 4{ }^{\prime}$ & -0.18 & 0.12 & .14 & {$[-0.42 ; 0.06]$} \\
Total effects & $\mathrm{c} 1$ & 0.26 & 0.16 & $<.10$ & {$[-0.02 ; 0.61]$} \\
Of cultural intelligence & $\mathrm{c} 2$ & 0.06 & 0.13 & .65 & {$[-0.21 ; 0.32]$} \\
On expatriate career intentions & $\mathrm{c} 3$ & 0.75 & 0.16 & $<.001$ & {$[0.47 ; 1.07]$} \\
& $\mathrm{c} 4$ & -0.06 & 0.16 & .69 & {$[-0.38 ; 0.25]$} \\
\hline
\end{tabular}

$N=469$

concluded that the data supported our theoretical expectations regarding the structural validity of the investigated constructs.

\section{Mediation analyses}

The mediation analyses were conducted in lavaan. The process model included the four dimensions of cultural intelligence as predictors of the mediator expatriate career self-efficacy, which predicted in turn expatriate career intentions. Because the distribution of indirect effects is not normal, it is usually recommended to use bootstrapping to obtain bias-corrected $95 \%$ confidence intervals for making statistical inference about indirect effects (Preacher \& Hayes, 2008). See Figure 1 for a representation of the path model, and Table 4 for corresponding path coefficients. Note that the fit of the mediation model was the same as the fit of the previously tested measurement model as the model was saturated.

About one-third of the total variation in expatriate career self-efficacy was explained by cultural intelligence $\left(R^{2}=.34\right)$. Cultural intelligence and expatriate career self-efficacy explained about two-thirds of the total variation in expatriate career intentions $\left(R^{2}=.62\right)$. Our analyses revealed that only the total effect of motivational $C Q$ on expatriate career intentions was significant $(B=.75, p<.001)$. Motivational CQ was also a predictor of expatriate career self-efficacy $(B=.61, p<.001)$. Expatriate career self-efficacy was in turn a significant predictor of expatriate career intentions $(B=1.03, p<.001)$. To test more thoroughly the mediation, we computed the indirect effect and its $95 \%$ bias-corrected bootstrap confidence interval with 10000 bootstrap samples. When the interval does not include 0 , we can conclude that the indirect effect is significant. We found that expatriate career self-efficacy 
significantly mediated the effect of motivational CQ on expatriate career intentions $(B=.63,95 \%$ Bootstrap Confidence Interval $=[0.40 ; 0.88])$.

\section{Discussion}

Our aim with Study 2 was to test a model inspired from the Career Self-Management model (Lent \& Brown, 2013) in which expatriate career self-efficacy was conceptualized as a mediator of the relationship between cultural intelligence-and especially its motivational dimension - and expatriate career intentions. The originally hypothesized model was only partly confirmed as only paths a3, b and c'3 were confirmed (see Figure 1; Table 4). This shows that unlike our hypothesized model, where expatriate career self-efficacy mediated the relation between all four cultural intelligence dimensions, only the relation between motivational CQ and expatriate career intentions, mediated by expatriate career self-efficacy is statistically significant. Our findings support the model by showing that (1) motivational cultural intelligence is positively related to expatriate career intentions, and that (2) this relationship becomes non significant when controlling for expatriate career selfefficacy, indicating mediation, which was confirmed by more advanced statistical tests.

\section{General discussion}

Our aim with the present research was to further understand the relationship between cultural intelligence and expatriate career intentions by providing evidence (1) for the incremental predictive power of cultural intelligence over and beyond emotional intelligence and personality, and (2) for the mediating role of expatriate career selfefficacy. The findings of our two empirical studies support our hypotheses. These findings have several theoretical and practical implications.

The findings about the incremental validity of cultural intelligence show that the relationship between cultural intelligence and expatriate career intentions cannot be fully explained by the fact that culturally intelligent individuals are also more emotionally intelligent or have specific personality characteristics that make them more likely to adjust to new cultures and therefore more willing to work in a foreign country. In other words, the construct of cultural intelligence taps into something specific that goes beyond emotional intelligence and personality and this something specific is a relevant predictor of expatriate career intentions. From a theoretical viewpoint, our findings suggest that the skills that differentiate cultural intelligence from emotional intelligence-especially the confidence in one's abilities to deal with cultural differences and the motivation to learn about cultures (Crowne, 2009)—contribute to expatriate career intentions. Our findings also suggest that the traits that differentiate cultural intelligence from personality - such as the openness to new cultural experiences or the self-efficacy beliefs pertaining to the ability to adjust to culturally diverse environments - contribute to expatriate career intentions. More specifically, our studies show that it is the motivational dimension of cultural intelligence that 
predicts expatriate career intentions, mediated by expatriate career self-efficacy, suggesting that motivational cultural intelligence plays a key role in expatriate career self-efficacy, and, in turn, in predicting expatriate career intentions. More research using specific measures of the traits listed before could be conducted in order to test more thoroughly our suggestions.

For practitioners seeking to develop monitoring programs to detect students who have low intentions to expatriate, our findings suggest that it seems relevant to incorporate cultural intelligence as it adds to the prediction of intentions to expatriate among students over and beyond more traditional constructs such as emotional intelligence and personality. Some institutions aim at fostering expatriation among students because the number of alumni who expatriated is a direct performance indicator for them. The rate of expatriation among alumni is often used, for example, to rank business schools. Our findings suggest that if the objective of a practitioner is to favor expatriation, s/he should pay close attention to students with low levels of motivational cultural intelligence as they might be less likely to intend to work abroad in the future. Note that future research measuring expatriation behaviors might be interesting to investigate whether cultural intelligence predicts expatriate decisions, and not only intentions.

Our findings regarding the mediating role of self-efficacy are in continuation with different earlier studies. We replicated previously theorized and observed relationships between cultural intelligence and expatriate career intentions (Krishnan \& Kirubamoorthy, 2017; Presbitero \& Quita, 2017; Schlägel \& Sarstedt, 2016) and expatriate career self-efficacy and expatriate career intentions (Weerasinghe \& Kumar, 2015). Importantly, whereas previous research investigated these relationships in isolation, the current work is the first to place and test these constructs within one theoretical model inspired by the Career Self-Management model (Lent \& Brown, 2013). According to the Career Self-Management model, career goals, actions and outcomes are highly dependent on self-efficacy beliefs which are themselves dependent on resources including learning experiences and personal inputs (personality, abilities and predispositions). In line with the Career Self-Management model, our findings suggest that individuals with resources to cope with cultural challenges have higher levels of expatriate self-efficacy beliefs, which make them in turn more willing to pursue a career in a foreign country. We found that it especially the motivational dimension of cultural intelligence-which measures the motivation as well as the confidence or the self-efficacy needed to deal with cultural diversity-that contributes to self-efficacy beliefs regarding expatriation. The fact that our direct effects were rendered non-significant after controlling for expatriate career self-efficacy, suggests that, at least in our population, alternate mechanisms may not play a significant role.

The findings of our second study suggest that expatriate career self-efficacy explains the relationship between cultural intelligence and expatriate career intentions, which means that cultural intelligence does not really add anything over and beyond self-efficacy when predicting expatriate career intentions. Practitioners who are only interested in predicting intentions might therefore not need to use the construct of cultural intelligence. However, cultural intelligence has been shown to predict many outcomes, and not only intentions to expatriate. For example, cultural 
intelligence is predictive of the cross-cultural adjustment and the performance of expatriates, but also of the efficiency of cultural decision making (Van Dyne et al., 2008). We therefore recommend practitioners to include cultural intelligence in their monitoring systems along with emotional intelligence and personality which predict other important academic outcomes as cultural intelligence can predict additional cultural outcomes that might be of interest.

The findings of the second study might also have implications for the development of training modules. Many empirical studies have shown that cross-cultural training has an impact on cultural intelligence (Bücker \& Korzilius, 2015; Fischer, 2011; MacNab, 2012; MacNab \& Worthley, 2012; Moon, 2010; Ott \& Michailova, 2018; Reichard et al., 2015). From a practical point of view our findings could suggest that in cross-cultural training courses, emphasis should be placed on developing expatriate career self-efficacy. Notably, to foster expatriate intentions among students, practitioners, but also teachers, could build interventions and teaching methods that integrate methods to nurture cultural intelligence with methods to develop expatriate career self-efficacy. Practitioners could, for example, not only train their clients to understand how cultures can differ, but also explicitly introduce concrete ways of how clients' could deal with specific cultural career challenges, due to certain cultural differences. Such interventions and training could boost clients' confidence and develop their cross-cultural conflict resolution preparedness and capabilities, and in turn, their willingness to pursue a career in another country.

Our study has limitations. A first limitation is that our study design was correlational. A correlational design makes it difficult to draw firm conclusions regarding the direction of relationships and the role of each variable in explaining the contribution of cultural intelligence to expatriate career intentions. Although emotional intelligence was not related to expatriate career intentions, it is possible that emotional intelligence, measured as an ability, also plays a mediating role in the relationship between cultural intelligence and expatriate career intentions. Cultural intelligence as a resource to cope with cultural challenges could indeed facilitate the use of efficient emotion regulation strategies, which could in turn influence self-efficacy beliefs or even directly influence expatriate intentions. Future research could therefore address alternative models that explain the link between cultural intelligence and expatriate career intentions. Emotional intelligence as an ability could be part of a serial mediation model between cultural intelligence and self-efficacy, or could be part of a parallel mediation model next to self-efficacy. Testing alternative models could provide valuable insights about the mechanism through which cultural intelligence contributes to expatriate career intentions.

Another limitation of our study is that we tested our hypotheses in a student population, which precludes drawing conclusions about other populations such as the population of workers, or unemployed individuals. On the other hand, the question of expatriate career intentions is especially relevant among university students, and as such the current study makes an important contribution. We invite other researchers to replicate our study in other populations to investigate the generalizability, but also the possible boundary conditions of our findings. 
Indeed, our studies did not include moderators although several moderators may be of importance both regarding cultural intelligence and the relationship between expatriate career self-efficacy and expatriate career intentions. For example, the study domain has likely an impact on the relationship between cultural intelligence and expatriate career intentions. The empirical literature already shows that expatriation is more likely in some jobs than in others (Finaccord, 2014). It is possible that in domains in which expatriation is less frequent, the level of cultural intelligence is less strongly related to expatriate career intentions as individuals, independent of their level of cultural intelligence, do not really expect that they will work abroad and therefore do not express intentions to expatriate. Further research is needed to better identify when cultural intelligence is especially relevant in predicting expatriate career intentions.

\section{References}

Ang, S., \& Van Dyne, L. (2015). Handbook of cultural intelligence. New York: Routledge.

Ang, S., Van Dyne, L., \& Koh, C. (2006). Personality correlates of the four-factor model of cultural intelligence. Group \& Organization Management, 31(1), 100-123. https://doi.org/10.1177/10596 01105275267.

Ang, S., Van Dyne, L., Koh, C., Ng, K. Y., Templer, K. J., Tay, C., \& Chandrasekar, N. A. (2007). Cultural intelligence: Its measurement and effects on cultural judgment and decision making, cultural adaptation and task performance. Management and Organization Review, 3(3), 335-371. https://doi.org/10.1111/j.1740-8784.2007.00082.x.

Bandura, A. (1977). Self-efficacy: Toward a unifying theory of behavioral change. Psychological Review, 84(2), 191-215. https://doi.org/10.1037/0033-295X.84.2.191.

Brislin, R., Worthley, R., \& Macnab, B. (2006). Cultural intelligence understanding behaviors that serve people's goals. Group \& Organization Management, 31(1), 40-55. https://doi. org/10.1177/1059601105275262.

Bücker, J. J., \& Korzilius, H. (2015). Developing cultural intelligence: Assessing the effect of the ecotonos cultural simulation game for international business students. The International Journal of Human Resource Management, 26(15), 1995-2014. https://doi.org/10.1080/09585 192.2015.1041759.

Caligiuri, P. (2001). Selecting expatriates for personality characteristics: A moderating effect of personality on the relationship between host national contact and cross-cultural adjustment. Management International Review, 40(1), 61-80.

Caligiuri, P., \& Bonache, J. (2016). Evolving and enduring challenges in global mobility. Journal of World Business, 51(1), 127-141. https://doi.org/10.1016/j.jwb.2015.10.001.

Coetzee, M., \& Harry, N. (2014). Emotional intelligence as a predictor of employees' career adaptability. Journal of Vocational Behavior, 84(1), 90-97. https://doi.org/10.1016/j.jvb.2013.09.001.

Crowne, K. A. (2009). The relationships among social intelligence, emotional intelligence and cultural intelligence. Organization Management Journal, 6(3), 148-163. https://doi.org/10.1057/ omj.2009.20.

Doherty, N., Richardson, J., Thorn, K., Doherty, N., Richardson, J., \& Thorn, K. (2013). Self-initiated expatriation: Career experiences, processes and outcomes. Career Development International, 18(1), 6-11. https://doi.org/10.1108/13620431311305917.

Earley, P. C., \& Mosakowski, E. (2004). Cultural intelligence. Harvard Business Review, 82(10), $139-146$.

Fang, Y., Jiang, G.-L. F., Makino, S., \& Beamish, P. W. (2010). Multinational firm knowledge, use of expatriates, and foreign subsidiary performance. Journal of Management Studies, 47(1), 27-54. https://doi.org/10.1111/j.1467-6486.2009.00850.x. 
Finaccord Ltd. (2014, November). Global Trends in Expatriate Demographics. Global trends in expatriate bancassurance models. Demographics around the world. Report presented at the International Travel and Health Insurance Conference ITIC, Venice, Italy.

Fischer, R. (2011). Cross-cultural training effects on cultural essentialism beliefs and cultural intelligence. International Journal of Intercultural Relations, 35(6), 767-775. https://doi. org/10.1016/j.ijintrel.2011.08.005.

Gosling, S. D., Rentfrow, P. J., \& Swann, W. B., Jr. (2003). A very brief measure of the Big-Five personality domains. Journal of Research in Personality, 37(6), 504-528. https://doi.org/10.1016/ S0092-6566(03)00046-1.

Harari, M. B., Reaves, A. C., Beane, D. A., Laginess, A. J., \& Viswesvaran, C. (2018). Personality and expatriate adjustment: A meta-analysis. Journal of Occupational and Organizational Psychology, 91(3), 486-517. https://doi.org/10.1111/joop.12215.

Ireland, G., \& Lent, R. (2018). Career exploration and decision-making learning experiences: A test of the career self-management model. Journal of Vocational Behavior, 106, 37-47. https://doi. org/10.1016/j.jvb.2017.11.004.

Konanahalli, A., \& Oyedele, L. (2016). Emotional intelligence and British expatriates' cross-cultural adjustment in international construction projects. Construction Management \& Economics, 34(11), 751-768. https://doi.org/10.1080/01446193.2016.1213399.

Koveshnikov, A., Wechtler, H., \& Dejoux, C. (2014). Cross-cultural adjustment of expatriates: The role of emotional intelligence and gender. Journal of World Business, 49(3), 362-371. https:// doi.org/10.1016/j.jwb.2013.07.001.

Krishnan, S., \& Kirubamoorthy, G. (2017). Cultural intelligence and cross-cultural adjustments: Impact on global mobility intentions. American Journal of Economics, 7(1), 25-28. https://doi. org/10.5923/j.economics.20170701.03.

Lee, L.-Y., Veasna, S., \& Sukoco, B. M. (2014). The antecedents of cultural effectiveness of expatriation: Moderating effects of psychological contracts. Asia Pacific Journal of Human Resources, 52(2), 215-233. https://doi.org/10.1111/j.1744-7941.2013.00055.x.

Lent, R. W., \& Brown, S. D. (2013). Social cognitive model of career self-management: Toward a unifying view of adaptive career behavior across the life span. Journal of Counseling Psychology, 60(4), 557. https://doi.org/10.1037/a0033446.

Lent, R. W., Brown, S. D., \& Hackett, G. (1994). Toward a unifying social cognitive theory of career and academic interest, choice, and performance. Journal of Vocational Behavior, 45(1), 79-122. https://doi.org/10.1006/jvbe.1994.1027.

Li, Z., \& Lowe, J. (2016). Mobile student to mobile worker: The role of universities in the "war for talent”. British Journal of Sociology of Education, 37(1), 11-29. https://doi.org/10.1080/01425 692.2015.1095636.

Lim, R. H., Lent, R. W., \& Penn, L. T. (2016). Prediction of job search intentions and behaviors: Testing the social cognitive model of career self-management. Journal of Counseling Psychology, 63, 594-603. https://doi.org/10.1037/cou0000154.

Lin, Y., Chen, A. S., \& Song, Y. (2012). Does your intelligence help to survive in a foreign jungle? The effects of cultural intelligence and emotional intelligence on cross-cultural adjustment. International Journal of Intercultural Relations, 36, 541-552. https://doi.org/10.1016/j.ijint rel.2012.03.001.

Liu, X., \& Giroud, A. (2016). International knowledge flows in the context of emerging-economy NNEs and increasing global mobility. International Business Review, 25(1), 125-129. https:// doi.org/10.1016/j.ibusrev.2015.07.008.

MacNab, B. R. (2012). An experiential approach to cultural intelligence education. Journal of Management Education, 36(1), 66-94. https://doi.org/10.1177/1052562911412587.

MacNab, B. R., \& Worthley, R. (2012). Individual characteristics as predictors of cultural intelligence development: The relevance of self-efficacy. International Journal of Intercultural Relations, 36(1), 62-71. https://doi.org/10.1016/j.ijintrel.2010.12.001.

Moon, T. (2010). Organizational cultural intelligence: Dynamic capability perspective. Group \& Organization Management, 35(4), 456-493. https://doi.org/10.1177/1059601110378295.

Myszkowski, N., Storme, M., \& Tavani, J. (2018). Are reflective models appropriate for very short scales? Proofs of concept of formative models using the ten-item personality inventory. Journal of Personality. https://doi.org/10.1111/jopy.12395.

Ott, D. L., \& Michailova, S. (2018). Cultural intelligence: A review and new research avenues. International Journal of Management Reviews, 20, 99-119. https://doi.org/10.1111/ijmr.12118. 
Pérez, J. B., \& Pla-Barber, J. (2005). When are international managers a cost effective solution? The rationale of transaction cost economics applied to staffing decisions in mncs. Journal of Business Research, 58(10), 1320-1329. https://doi.org/10.1016/j.jbusres.2004.05.004.

Preacher, K. J., \& Hayes, A. F. (2008). Contemporary approaches to assessing mediation in communication research. In F. Hayes, M. D. Slater, \& L. B. Snyder (Eds.), The sage sourcebook of advanced data analysis methods for communication research (pp. 13-54). Thousand Oaks, CA: Sage.

Presbitero, A., \& Quita, C. (2017). Expatriate career intentions: Links to career adaptability and cultural intelligence. Journal of Vocational Behavior, 98, 118-126. https://doi.org/10.1016/j. jvb.2016.11.001.

Reichard, R. J., Serrano, S. A., Condren, M., Wilder, N., Dollwet, M., \& Wang, W. (2015). Engagement in cultural trigger events in the development of cultural competence. Academy of Management Learning \& Education, 14(4), 461-481. https://doi.org/10.5465/amle.2013.0043.

Roche, M. K., Daskalova, P., \& Brown, S. D. (2017). Anticipated multiple role management in emerging adults: A test of the social cognitive career self-management model. Journal of Career Assessment, 25(1), 121-134. https://doi.org/10.1177/1069072716658654.

Rosseel, Y. (2012). Lavaan: An r package for structural equation modeling. Journal of Statistical Software, 48(2), 1-36. https://doi.org/10.18637/jss.v048.i02.

Schlägel, C., \& Sarstedt, M. (2016). Assessing the measurement invariance of the four-dimensional cultural intelligence scale across countries: A composite model approach. European Management Journal, 34(6), 633-649. https://doi.org/10.1016/j.emj.2016.06.002.

Storme, M., Tavani, J.-L., \& Myszkowski, N. (2016). Psychometric properties of the French tenitem personality inventory (tipi). Journal of Individual Differences, 37(2), 81-87. https://doi. org/10.1027/1614-0001/a000204.

Vaiman, V., Haslberger, A., \& Vance, C. M. (2015). Recognizing the important role of self-initiated expatriates in effective global talent management. Human Resource Management Review, 25(3), 280286. https://doi.org/10.1016/j.hrmr.2015.04.004.

Van Dyne, L., Ang, S., \& Koh, C. (2008). Development and validation of the CQS. In S. Ang \& L. Van Dyne (Eds.), Handbook of cultural intelligence (pp. 16-40). New York: Routledge.

Weerasinghe, C., \& Kumar, S. (2015). Intention to pursue overseas jobs among university students and graduates: A case study from university of Peradeniya, Sri Lanka. Tropical Agricultural Research. https://doi.org/10.4038/tar.v26i1.8075.

Wirth, R., \& Edwards, M. C. (2007). Item factor analysis: Current approaches and future directions. Psychological Methods, 12(1), 58.

Wong, C.-S., \& Law, K. S. (2002). The effects of leader and follower emotional intelligence on performance and attitude: An exploratory study. The Leadership Quarterly, 13(3), 243-274. https://doi. org/10.1016/S1048-9843(02)00099-1.

Publisher's Note Springer Nature remains neutral with regard to jurisdictional claims in published maps and institutional affiliations. 